\title{
Library-Vendor Relations: Data from a Survey of Libraries and of Vendors [dataset]
}

\section{Author: Kirsten Ostergaard, Doralyn Rossmann}

DOI

http://doi.org/10.15788/M2G599

Date uploaded

February 2016

\section{Description}

The dataset includes the results of two surveys created to evaluate the library-vendor relationship. One survey includes results from academic library professionals and the other from vendor professionals.

\section{Associated article}

Kirsten Ostergaard \& Doralyn Rossmann (2017) There's Work to be Done: Exploring LibraryVendor Relations, Technical Services Quarterly, 34:1, 13-33.

https://doi.org/10.1080/07317131.2017.1238196

\section{Citation}

Ostergaard K \& Rossmann D (2016) Library-Vendor Relations: Data from a Survey of Libraries and of Vendors [dataset]. Montana State University ScholarWorks.

http://doi.org/10.15788/M2G599 